\title{
EDUCATIONAL
} TECHNOLOGY

\section{Aussat and all that! Reaching the Australian outback}

\author{
Brian Fowler \\ School of Education \\ Darling Downs Institute of Advanced Education
}

The problem: Australia is a country of low population density, its 16 million people are concentrated on the eastern coastal fringes and capital cities. Of the $90 \%$ of the population which lives in cities and towns, $62 \%$ actually resides in the eight state or territory capitals. These residents are quite will supplied with educational facilities -unlike the remaining $10 \%$ who live in "the outback" or mountain regions who usually live at least 20 $\mathrm{km}$ (and in some cases over $100 \mathrm{~km}$ ) from their nearest neighbours, let alone a school. These families have always faced the problems of physical isolation and of obtaining an education for their children. In these situations their children must either travel up to three hours each way to the nearest one-teacher school or take tuition at home by correspondence. A third option, usually applicable for those with secondary school age children, is enrolment in boarding school. Whilst allowing a better social environment for the children, this latter option has the disadvantage of limiting severely their contact with the family. Another form of isolation is experienced by itinerant workers who are socially, rather than geographically, isolated. There are also a small number of children who for medical reasons are unable to partake in conventional schooling.

\section{Queensland}

Traditional solutions: At the turn of the century the Education Department addressed the problem of isolation by sending an itinerant teacher to visit hundreds of families several times during the year. By 1922 it had developed the Primary Correspondence School which at its peak in WW2 had over 7000 children enrolled. Last year its enrolments totalled over 1700 children up to Grade 7. All of its material is produced and marked in Brisbane. 
The correspondence material is divided into either weekly (grades 1 to 3) or fortnightly parts and includes audiotapes both as a teaching and as a feedback medium. The "Home Tutor", usually a parent or governess, has a vital role in organising, supervising and interpreting the correspondence material with the children

The first major application of non-profit technology was the introduction of the School of the Air (SOTA) in Cloncurry in 1960. By 1966 there were three SOTA centres - Mt Isa (moved from Cloncurry), Charleville and Charters Towers (later moved to Cairns). Each of these centres is associated with the Royal Flying Doctor Service and uses its radio network.

Charleville SOTA: Now the largest such centre in the world, employing 10 teachers catering for 385 primary age children within $1000 \mathrm{~km}$ of Charleville SOTA had only one teacher and 45 children when it started in 1966.

It provides supplementary material and contact for these children who are already using the Correspondence School material. The Correspondence School concentrates on written work, SOTA on oral, whilst trying to provide a classroom atmosphere for the children.

Schools of the Air bridge the oral communications gap in many ways. They:

- Provide a three way communication from teacher to child, child to teacher, and child to child;

- Assist the home tutor by explaining problems met in correspondence papers and answering queries directly;

- Enrich the written program with music, news and group activities such as plays and clubs.

- Develop a sense of closeness and of belonging to a special group or classroom;

- Motivate the pupils to improve the quality of response to correspondence lessons;

- Increase in pupils the dualities of self-confidence, initiative, self reliance and sense of responsibility; and

- Build a concept of a teaching team between the SOTA teacher, the child, the correspondence school teacher and the home tutor.

The child benefits from the feeling that the teacher is close at hand and the knowledge that he or she is being supported by the team approach of SOTA and PCS, and is motivated by hearing the response of his or her peers, to perform well. (Charleville School of the Air, "Information Booklet", 1986, page 3) 
There are regularly scheduled class times of half an hour each day for each class of 5 to 12 students. This 30 hours of air time each day is made possible by the use of five studios and five HF transmitters (two of which are shared with the Flying Doctor Service). The most frequent criticism of this service relates to the quality of reception which can be poor for those in difficult areas, and problematic for all during the stormy season.

Even with the variety in learning experiences provided by the SOTA the parents and children still feel that there is a need for a more personalised system, in which there is more immediacy of contact between the children and their teachers.

Satellite Technology: Two AUSSAT satellites were launched in late 1985 whose beams not only cover the whole of the continent, but are also able to focus on four individual "footprints". Families and schools with a suitable receiving dish are able to receive $A B C$ television and radio programs, many for the first time, in most cases with satisfactory reception for the first time. This is known as the Homestead and Community Broadcast Satellite Service (HACBSS) and is the major direct benefit to these isolated families and schools. By April this year they will be able to receive commercial television programs as well.

Q-NET provisions: It is not only the isolated family that has benefited from the new technology - many small schools (some with as few as 10 children) can also benefit from this technology. On a regular basis educational programs are transmitted during non-peak time and recorded at the earth stations. These can be distributed to a number of schools in the immediate region.

This video link will be extended in 1987 to include two-way data linkages between computers at suitable centres. This will enable the exchange of text, pictures, messages and computer software. Centres which do not have suitable earth stations will continue to use telephone lines for this purpose.

The Mount Isa Satellite Trial: The launching of the AUSSAT satellites has facilitated the trialing of a most innovative development in the application of advanced educational technology to primary school distance education. For the first time in any country, primary education is being enhanced by the use of satellites communicating directly into a child's own home. It is emphasised however that this was strictly a trial to investigate the educational possibilities of this form of high technology communication. From its inception in 1984, the consideration of educative processes dominated the planning and specification of the "trial" system.

Before looking at the specific educational goals of the system we should outline its nature and features. 
Eight isolated families with Grade 6 children were selected from the Mt Isa SOTA participants. These families were loaned a small two-way earth station and associated equipment, together with an Apple IIe computer system and selected software. The children continue as PCS students, but use written materials specifically adapted for the trial. Another change is that the written assignments are returned to their SOTA teacher at Mt Isa instead of being returned to Brisbane. These lessons are complimented by the satellite communications instead of the normal HF radio contact. There are two half-hour sessions each morning at 8.30 and $11 \mathrm{am}$. In the earlier session the children take part in group activities such as debating and the sharing of problem-solving tasks. The second session is used to clarify and revise the correspondence material in teacher-directed lessons in both oneto-one and whole group situations.

In these sessions there is clear and immediate two-way interaction between the teacher and children, and between the children themselves. By the use of specifically designed communications software the children can send text or graphics files to the teacher, and both can discuss the material whilst seeing it on their computer monitors. The teacher can also send text or graphics either to an individual child or to the whole class for discussion. he can also control the cursor on all computers to indicate specific items on the transmitter image, or he can assign that control of the cursor to a child who can then point to items or add information on all screens.

A third half-hour is available for the transmission of data to and from the child for marking of work, and for teacher/home tutor conferencing. Further help is given to the home tutors in a fortnightly session which outlines new work to be done in the next fortnight period and also gets consoles that they can use to call up their teacher for help at any time of the school day.

In addition, each fortnight, a video program originates in Brisbane for these children. In this program the children can see the presenter and can use the two- way link in an interactive situation. In these sessions the Brisbane presenter can ask questions of the children or (as in later programs) get the children to discuss problems depicted in a role-playing situation. Science experiments can also be demonstrated for home replicating. The specially adapted learning package also includes videotapes and audiotapes.

The project team is very pleased with the system and feels that it has met all its objectives. The first of these goals was to "provide personalised, interactive and educational experiences for geographically isolated primary school pupils". In meeting this objective the system successfully provided a fully interactive environment with telephone clear sound. The 
children felt that they were part of a real group. They were even able to send messages to each other, via a computer "mailbox" in Mt Isa, outside of regularly scheduled school times. All of the planned experiences worked well, ranging from debating and group investigation to creative experiences such as music and art. Social skills were seen as being important as was the "social" contact with school friends whom they might otherwise only meet once or twice a year. Students also were able to successfully contribute to the decisions that affected their educational program. It was also found that the clarity of the communication when using headphones facilitated very strong concentration by the children.

The second goal related to the communication system itself; "to examine procedures for assisting pupils to gain the knowledge, skills and attitudes necessary to use effectively the system under trial" / The children had no trouble adapting to the requirements of the system and found it to be an outstanding improvement over their previous HF radio experience. The equipment has given no trouble, after the usual minor installation teething problems, even under the fairly adverse physical conditions prevalent in outback conditions.

The third goal was "to study procedures for localising the delivery and management of distance education programs". The PCS normally marks all materials in Brisbane with the SOTA assuming a complementary role. The "trial" showed that the SOTA could successfully provide more effective and individualised control of the students" learning. The home tutors were quite happy with this more direct contact between the children and their teacher, and also with the greater individualisation which was possible. The provision of the "call button" was also appreciated by the home tutor and children alike. It has meant that the home tutor has had some of the supervision load lifted from her.

When the trial is continued in 1987, all the children in these same families will operate as a "family grouping" and some more sophisticated techniques, particularly in the area of graphics, will be tried.

\section{Western Australia}

Similar problems of isolation are experienced in the state of Western Australia, a large proportion of which is classified as desert. In fact $75 \%$ of the state's population lives in Perth, and much of the remainder lives in the SW corner of the state, south of Perth. For these reasons the state government is watching the Q-Net developments and the Mt Isa Trial with considerable interest. 
Western Australia has five SOTA centres which serve a total of 135 students. There is a proposal to use the satellite in a "Mixed technology" mode; ie. to broadcast from the SOTAs on both JF radio and via the satellite, and to allow three alternative return paths for the children. These return paths should be - HF radio, telephone or satellite. (Satellite Project Team, The Domestic Satellite and Schools of the Air, Ed. Dept. of WA 1985).

A commercial broadcaster is also using the satellite for educational broadcasting. The Golden West Network transmits one and a half hours of educational material each morning. These transmissions cover a wide range of programs, from traditional types of educational films to professional development and continuing- education materials. As this Network uses a high powered transponder the telecasts are readily received by individuals or communities with a small receiving dish. Some programs take the form of a "School of the Air" which incorporates an interactive component in which students are encouraged to phone the answers are heard by all the students, thus giving a better feeling of participation for the children. These programs are also broadcast on GWN's regional commercial television network simultaneously allowing a wider range of students to participate.

A third educational service which GWN provides is the late-night broadcasting of educational materials which are intended for automatic recording by schools and students in their homes. The Western Australian College of Advanced Education has also used these broadcasts to download material to its BEd students.

A venture established in 1985 by the WA Schools Computing Branch was to trial electronic mail communications between a number of its country high schools using microcomputers connected to the telephone network. Of particular interest to this paper is the recently acquired ability of teachers and students in isolated schools to communicate with their counterparts in other schools. The advantage to the students in these high schools is the facility to establish and communicate with electronic penpals. They can also use word processing for their assignments and can exchange their work with others, and are even able to obtain a sample copy of a "good" assignment.

The advantages of this electronic mail system for teachers in small schools is that they now have ready access to educational data-bases, curriculum bulletin boards and to VIATEL, the public videotex data-base. 


\section{South Australia}

The Educational Technology Centre in Adelaide has been involved in trials of various types of technology for distance education since at least 1979 as a precursor to the arrival of the satellite. There is one SOTA at Port Augusta, but there are many small schools, some of which have only a handful of secondary school age children.

Most of the formal trials, using advanced technology, have been with these small isolated schools. One, in the early eighties, was with Tarcoola School which is $800 \mathrm{~km}$ from Adelaide at the junction of the main North-South and East-West railways. At the time Tarcoola School had 60 children aged 5 - 17 years, together with 3 primary and 2 secondary teachers. The main aim was to test a range of teaching methodologies with a variety of students using such media as slow scan TV, loudspeaking telephones and facsimile machines, all of which were connected to the telephone network. The trial was successful in that it allowed solutions to technical and organisational problems to be found, and in that it highlighted the potential of the loudspeaking telephone for use with individuals and small groups.

Other activities in the early eighties were the involvement in the Federal Government's Loan Video Scheme (142 children) and in using the ATS-1 satellite for communications between Adelaide and some near Pacific centres. The Loan Video Scheme enabled state Education Departments to copy some ABC School's Broadcasts and lend them together with others that they themselves had produced. These were distributed fortnightly to the families who were also able to borrow a video recorder if necessary.

1983-4 saw trials which concentrated upon the use of loudspeaking telephones in small schools in such diverse subjects as oral French and Italian for small groups of senior children, flute making and playing for primary age children, and the playing of percussion instruments. This latter program has now become a regular fixture at Eyre High School in Whyalla in the iron triangle area west of Spencer Gulf. A teacher in an Adelaide School runs a specially scheduled class after school for a group of students (which have been gathered from various high schools in Whyalla) using a loudspeaker telephone system.

In 1984-5 a special music theory program was also conducted from a metropolitan high school, however in this instance it was for one musically talented student at Jamestown High School some $200 \mathrm{~km}$ away. The problem was that there was no suitably qualifies music teacher to teach the theory component of the course, although a local private teacher could handle the practical component. A loudspeaking telephone was installed in the Adelaide classroom (the "hub class") and the distant 
students was able to participate in the class activities via the telephone line. The student completed the two year course successfully such as to seek entrance to a tertiary music course. This form of "hub" class activity has now been taken up by a number of schools in order to assist other smaller schools who have these types of needs.

The findings and conclusions from these trials include the following, many of which are fairly obvious, but were found to be crucial to the success of the various applications.

1. Visual material is necessary, it should preferably be sent to the distant students well before the lesson. This may be in the form of worksheets, class notes, diagrams, slides or videotapes.

2. The success of these types of systems depends very much on the skill of the presenting teacher and also upon his/her enthusiasm. In most cases the teacher must be very well organised.

3. The school timetable must be flexible enough to allow children to get to the studio for the "remote" class at the proper time. Sufficient time for private study and revision must also be timetabled.

4. It is necessary to plan to include slightly less content for a given period of time than would be normal.

5. Students need to be carefully selected and made aware of what is requires of them.

The South Australian ETC has apparently opted at this stage for the telephone network for their communications system (in contrast to Queensland's enthusiasm for satellite networking) and is in the process of setting up a number of regional telephone networks, some of them with dedicated lines. They have specifically developed the DUCT (Diverse Use of Communication Technology) equipment which allows multiconferencing by telephone landlines.

\section{Victoria}

Although Victoria is the smallest mainland state and has the highest population density it also has similar problems with small rural schools which are unable to offer a wide enough range of subjects for senior students. The aim of the Victorian Country Education Project trials has been to establish clusters of schools which can form networks and can share resources in a similar manner to the South Australian "hub" system. A cluster in East Gippsland had planned to start using two-way UHF radio, but have now switched to using a microwave link, whereby activities at Bairnsdale High School (940 Children) are transmitted to Orbost High School (less than 400) to provide one-way video and two-way audio communications. 
Other clusters are using two-way radio and loudspeaking telephones, particularly for teaching foreign languages. The main aim of all these activities is to maintain the viability of small schools and to encourage the children to stay on in senior classes.

To conclude the roundup of the Australian mainland states, we turn to the most populous of all the states, the state just south of Queensland. We also return to the problem of the isolated student rather than of the small school.

\section{New South Wales}

For the past three years the Primary Correspondence School in Sydney has experimented with electronic main to try to overcome the delay problem experienced by students. After the initial experiments in 1984 using videotex and facsimile machines which were frustrated by equipment problems, the team switched to IBM portable computers in 1985. Nine families with grade 5 children (10-11 years) were selected and were loaned the computer, videotex modem, colour monitor and facsimile machine. The curriculum materials that were used in the trial covered only mathematics and process writing, while the other children were able to send their process writing stories down the telephone line to the teacher who would add comments and send them back the same day. The speed of feedback, together with the novelty of the computer, encouraged them to write much more often and with a generally acknowledged improvement in quality.

The mathematics material was specially written for the trial, although initially it was simply a supplement tot he normal written material. Later LOGO was introduced to these students and used with great success.

The next stage also involved the introduction of the "First Fleet Database", together with the widening of the trial to include other members of the family and the use of electronic mail to allow the students to "chat" with each other and to send messages to their teacher. It was this latter facility which had the most impact upon the feelings of isolation felt by these families. A number commented that they felt they were a member of a "normal" class at last. The computer helped satisfy a great desire for communication in a number of cases, so that some students spent a lot of their spare time writing and sending messages. Even though they always had a telephone available, the cost of STD calls was previously prohibitive and therefore restricted their ability to contact children of their own age. 
The main benefits of this trial therefore were the increased turnaround speed which reduced delays from weeks to "same day", together with the increased feeling of belonging to a real class brought about by the messaging system.

These comments generally apply to all the trials, in that they all in their own way enabled children who felt isolated, either in a small school or at home, to participate in activities with children of their own age and interests. They all provided an opportunity, no matter how small, for these children to have access to some of the resources enjoyed by children in large schools, and to give them a better chance of success in their education.

Author: Brian Fowler is a lecturer in the School of Education, Darling

Downs Institute of Advanced Education, Toowoomba, Queensland 4350.

His original paper was presented to Association for Educational

Communications and Technology Conference, Atlanta, February 1987.

Please cite as: Fowler, B. (1987). Aussat and all that! Reaching the Australian outback. Australian Journal of Educational Technology, 3(2), 119-

128. http: / / www.ascilite.org.au / ajet/ ajet3 / fowler.html 